\title{
The representation and integration in memory of spatial and nonspatial information
}

\author{
TIMOTHY P. MCNAMARA, JOHN A. HALPIN, and JAMES K. HARDY \\ Vanderbilt University, Nashville, Tennessee
}

\begin{abstract}
A series of experiments investigated whether people could integrate nonspatial information about an object with their knowledge of the object's location in space. In Experiments 1 and 3 , subjects learned the locations of cities on a fictitious road map; in Experiments 2, 4, and 5, subjects were already familiar with the locations of buildings on a campus. The subjects then learned facts about the cities on the maps or the buildings on the campus. The question of interest was whether or not these nonspatial facts would be integrated in memory with the spatial knowledge. After learning the facts, subjects were given a location-judgment test in which they had to decide whether an object was in one region of the space or another. Knowledge integration was assessed by comparing levels of performance in two conditions: (a) when a city or a building name was primed by a fact about a neighboring city or building, and (b) when a city or a building name was primed by a fact about a distant city or building. Results showed that responses in Condition a were faster or more accurate, or both faster and more accurate, than responses in Condition $b$. These results indicate that the spatial and nonspatial information were encoded in a common memory representation.
\end{abstract}

When people learn the locations of objects in an environment, they typically acquire nonspatial information about the objects. For example, as students learn the locations of buildings on a campus, they also may learn which departments are housed in which buildings, the relative ages of the buildings, and whether or not a building's architectural style is pleasing. Indeed, as this example suggests, our spatial experiences with objects in an environment are often determined by both nonspatial and spatial properties of the objects.

The goal of the research described in this paper was to determine whether people could integrate nonspatial information about an object with their knowledge of the object's location in space. Specifically, participants in these experiments first learned a spatial layout, either a map or a real college campus, and then learned nonspatial verbal facts about cities on the map or buildings on the campus (e.g., "The city Sedona is noted for computer manufacturing" or "Alumni Hall is named for alumni who died in World War I"). Memories of maps and of natural environments are known to support diverse spatial behaviors, including image scanning (e.g., Kosslyn, Ball, \& Reiser, 1978), distance estimation (e.g., Baird, Merrill, \& Tannenbaum, 1979; Thorndyke, 1981), judg-

This research was supported in part by National Science Foundation Grants BNS-8417741 and BNS-8820224, a Spencer Fellowship from the National Academy of Education, and a grant from the James $S$. McDonnell Foundation. We are grateful to Jeanette Altarriba and Elizabeth McCullough for their assistance in various stages of the research, and to Diana Miller Sharp, Margaret Intons-Peterson, and three anonymous reviewers for their comments. Correspondence and requests for reprints should be sent to T. P. McNamara, Department of Psychology, 301 Wilson Hall, Vanderbilt University, Nashville, TN 37240. ments of relative direction (e.g., Stevens \& Coupe, 1978), and of course, navigation. The facts, on the other hand, expressed ideas that would be difficult to mentally represent in a spatial format. The question of interest was whether people could integrate these nonspatial facts with their mental representations of the spatial layouts.

There is no doubt that spatial memories are influenced by nonspatial information. Sixty years ago, Carmichael, Hogan, and Walter (1932) demonstrated that reproductions of visually presented figures were affected by the labels given to the figures (see also Bower, Karlin, \& Dueck, 1975; Daniel, 1972). More recently there have been several demonstrations of the effects of nonspatial semantic relations (e.g., "knife-fork") on the structure of spatial memories (e.g., Hirtle \& Mascolo, 1986; McNamara \& LeSueur, 1989; Sadalla, Staplin, \& Burroughs, 1979). Finally, one does not need experimental data to recognize that people can construct mental images of objects and scenes on the basis of verbal instructions to do so and, of course, talk about what they see.

These results and observations necessarily imply a connection between linguistic and spatial information; they do not imply, however, that verbally coded information has been integrated in a spatial representation. For example, the semantic relations shared by a set of objects could cause people to misrepresent interobject spatial relations (e.g., Hirtle \& Mascolo, 1986) without being encoded as part of the spatial representation. Likewise, the mental image that is produced in response to a request to imagine an object may not contain the verbal instructions to form the image or any other verbally coded information about the object; indeed, there are no reasons to expect that it would. 
Although the particular issue examined in this series of experiments has not been investigated previously, the general problem-whether or not visual-spatial and linguistic-nonspatial information can be integrated in memory-has a fairly long history. This problem first surfaced in the early investigations of the effects of misleading questions on eyewitness testimony (e.g., Loftus, 1975; Loftus, Miller, \& Burns, 1978), and it was examined systematically in a series of experiments on the effects of verbal statements on memories of pictures (Gentner \& Loftus, 1979; Pezdek, 1977; Rosenberg \& Simon, 1977). The results of these experiments seemed to indicate that visual and verbal information could be integrated in memory.

Pezdek (1977), for example, had subjects study a series of pictures (which depicted objects in various spatial arrangements), followed by a series of sentences. Each picture could be paired with a sentence that was semantically relevant or semantically irrelevant. The semantically relevant sentence embellished the picture in some way. For example, a picture of a car (sans ski rack) parked by a tree might be followed later by the sentence, "The car by the tree had a ski rack on it." A semantically irrelevant sentence might be, "The bird was perched atop the tree." Subjects then received a recognition test for the original pictures. Recognition performance was better when the intervening sentences provided no information about the pictures (semantically irrelevant) than when they provided misinformation about the pictures (semantically relevant). Pezdek concluded from these and related data that the pictures and the semantically relevant sentences had been integrated in memory.

Research by McCloskey and Zaragoza (1985) indicates that this conclusion was premature. McCloskey and Zaragoza showed that the results of the early experiments on the effects of misinformation on memory can be accounted for even if the misinformation was impotent. More to the point, these results do not necessarily imply that the visual and the verbal information were integrated in memory. In a recent examination of some of these issues, Belli (1989; see also Tversky \& Tuchin, 1989) showed that misleading information interferes with the ability to retrieve the details of an event, but even his studies could not distinguish between explanations that require knowledge integration (e.g., memory impairment) and those that do not (e.g., source misattribution).

The ability to form hybrid mental representations is also presupposed by some theories of reading comprehension. According to "mental model" theories (Johnson-Laird, 1983; Sanford \& Garrod, 1981; van Dijk \& Kintsch, $1983)$, readers not only process a text at a propositional level, they also construct a mental model that is analogous in structure to the events, situations, or layouts described in the text. Consider, for example, the following sentence (from Bransford, Barclay, \& Franks, 1972): "Three turtles rested on a floating log, and a fish swam beneath it." A mental model for this sentence might include three symbols corresponding to the turtles. These symbols, or tokens, might be represented as being on a token $\log$, which in turn might be represented as being above a token fish. Mental models are particularly useful for representing spatial information, but they also may contain information, such as goals, plans, and causal relations (Johnson-Laird, 1983), that cannot be represented spatially.

There is a large body of evidence consistent with the mental model framework (see, e.g., Franklin \& Tversky, 1990; Glenberg, Meyer, \& Lindem, 1987; Mani \& Johnson-Laird, 1982; McNamara, Miller, \& Bransford, 1991; Morrow, Bower, \& Greenspan, 1989; Morrow, Greenspan, \& Bower, 1987; Sharp \& McNamara, 1991; and other papers in this issue). This research has been very informative about the functional role of spatial information in reading comprehension. Even so, none of these studies has demonstrated that spatially coded and verbally coded information can be integrated in the same memory representation.

Our approach to this problem was much more direct than the approaches taken in previous research. The subjects first acquired a spatial layout. In Experiments 1 and 3 , we had them learn a road map, whereas in Experiments 2,4 , and 5 , we recruited subjects who were already familiar with the locations of buildings on a university campus. A critical subset of the locations on the maps and on the campus could be divided into pairs that were close together (e.g., Neely and Alumni Hall) and pairs that were far apart (e.g., Neely and Wesley Hall; see Figure 1).

In the second phase of the experiment, the subjects learned facts about the cities on the maps or the buildings on the campus. For example, they might have learned that Neely contains a dramatic theater, that Alumni Hall was named for alumni who died in World War I, and that Wesley Hall has a swimming pool in the basement. The question of interest was whether or not these nonspatial facts would be integrated in memory with the knowledge of the buildings' (or cities') locations.

After learning the facts, the subjects participated in a task in which they had to decide whether cities or buildings were in one region of the space or another. The facts and either city or building names appeared sequentially on a computer terminal screen; the subjects' task was to make a location judgment for each item. Knowledge integration was assessed by comparing performance in two experimental conditions: (a) when a city or a building name was primed by a fact about a neighboring city or building, and (b) when a city or a building name was primed by a fact about a distant city or building. We reasoned that if the spatial and the factual knowledge were integrated in memory, then a distance effect should be present in response latencies and accuracy: Responses to "Neely" should be faster and more accurate when primed by "World War I" (a fact about the neighboring building, Alumni Hall) than when primed by "swimming pool" (a fact about the distant building, Wesley Hall). In contrast, if the spatial and the factual knowledge were 


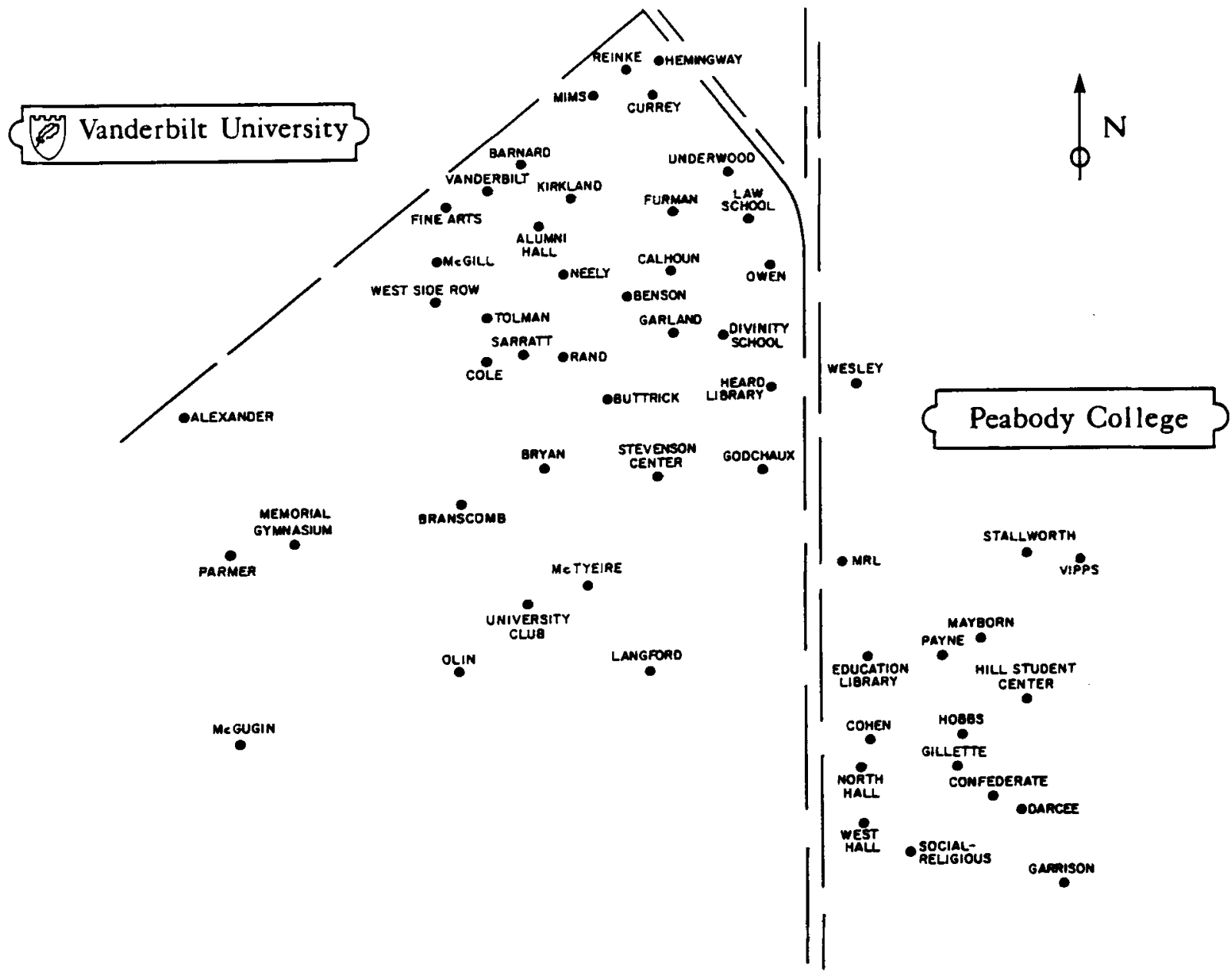

Figure 1. A map of the relative positions of selected buildings on the Vanderbilt University campus.

not integrated in memory, then a distance effect should not be present.

Priming has been an effective tool for investigating properties of spatial memory (e.g., Clayton \& Chattin, 1989; McNamara, 1986; McNamara, Ratcliff, \& McKoon, 1984). Priming is particularly useful for investigating knowledge integration because it does not seem to be influenced by retrieval strategies. Ratcliff and McKoon (1981) showed that priming in memory for text has a very fast onset and is insensitive to probability manipulations. McNamara, Hardy, and Hirtle (1989) have demonstrated further that inhibition does not occur in spatial priming at brief $(150-\mathrm{msec})$ stimulus onset asynchronies. These qualities indicate that priming is an automatic process (as defined by Posner \& Snyder, 1975a, 1975b). Consequently, with the appropriate experimental controls, priming should be informative about the structure and the content of memory, rather than strategies and inferences employed at the time of testing (Tulving, 1976).
We used different methods across the five experiments to establish the generality of our findings. In Experiments 1 and 3, the subjects learned the locations of cities on fictitious road maps and then learned facts about the cities; in Experiments 2, 4, and 5, they learned facts about buildings on their campus, and consequently, the spatial layout was learned naturally, prior to the experiment. Furthermore, in one of the map-learning experiments, the subjects studied maps drawn on paper; in the other, map and fact learning were controlled by a computer so that spatially contiguous cities always appeared far apart in the acquisition order (Clayton \& Habibi, 1991; Sherman \& Lim, 1991). Finally, in the location-judgment task used in Experiments 1 and 2, the subjects saw a series of fact predicates and city or building names, and had to make a decision on each item, including fact predicates; in the other three experiments, a trial in the location-judgment task consisted of the presentation of a fact (the prime) for a short period of time, followed by a city or a building 


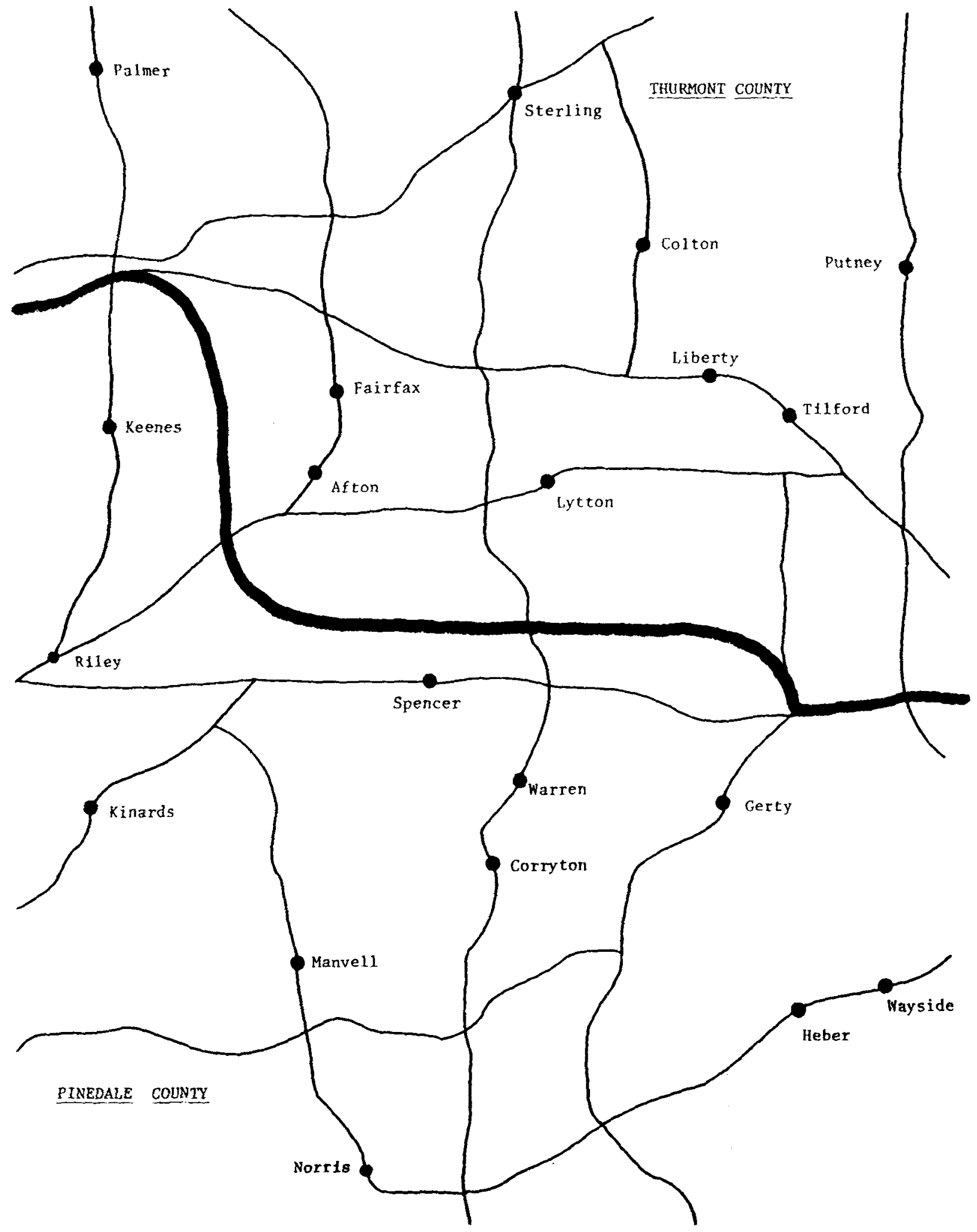

Figure 2. One of the maps used in Experiments 1 and 3. 
name (the target), and the subjects' task was to respond to the target only. In sum, if the same results appear in all five experiments, they cannot easily be attributed to peculiar aspects of the materials or the procedures.

\section{EXPERIMENT 1}

In Experiment 1, the subjects first learned a fictitious road map, which was divided into two counties. Certain pairs of cities were close together and others were far apart. In Figure 2, for example, Warren and Corryton are in the close condition, and Keenes and Manvell are in the far condition.

The subjects then learned facts about the cities on the map. For example, they learned that Warren is famous for its large amusement park, that Corryton has a modern metropolitan airport, that Manvell is a principal manufacturer of chemicals, and that Keenes has a population of 820,000 people. After learning the facts, the subjects received a location-judgment test. A series of city names and facts was presented one item at a time on a computer terminal; the subjects' task was to decide whether each city was in County A (e.g., Thurmont) or County B (e.g., Pinedale), and whether each fact was associated with a city in County A or B. On the test list, the fact "airport" (associated with Corryton) might immediately precede "Warren," and the fact " 820,000 people" (associated with Keenes) might immediately precede "Manvell." The question of interest was whether decisions for "Warren" would be faster than those for "Manvell." The existence of priming would indicate that the facts and the city locations were encoded in a common memory representation.

Two methodological details are worth noting. First, the facts that appeared in the location-judgment test never included city names. If city names had been part of these items, then direct priming between a city and its neighbor could have occurred in subjects' memories of the maps. Second, a fact was never followed by the city name with which the fact was associated (but see Experiments 4 and 5). Priming would almost certainly appear in such a situation, but it would not be informative about knowledge integration.

\section{Method}

\section{Subjects}

The subjects were 24 undergraduate students at Vanderbilt University. All subjects were selected on a voluntary basis from an introductory psychology course and received both laboratory credit and monetary compensation for their participation.

\section{Materials and Design}

Maps. Two road maps were constructed, each of which contained the locations of 20 cities. The locations on a map could be divided into eight pairs of experimental locations, and four filler locations. The experimental locations could be further divided into four pairs separated by 0.75 in. (close pairs) and four pairs separated by 5.00 in. (far pairs). Half of each of these types of items appeared in the upper county, and half appeared in the lower county. The maps were drawn on $8.5 \times 11$ in. sheets of paper.

A pool of 44 names was selected from a road atlas, with the restriction that the names be unfamiliar to Vanderbilt students and that no more than 4 of the names begin with the same first letter. For each map, 22 unique names were randomly drawn from this pool. Twenty of these names were used to name city locations and 2 were used to name the counties.

A second version of each map was constructed by changing the locations of the eight experimental pairs of cities, such that cities far from one another in Euclidean distance were now close to one another, and vice versa. On the map in Figure 2, Warren and Corryton are in the close condition and Keenes and Manvell are in the far condition. On the other version of this map, these pairs of cities swapped locations, so that Warren and Corryton were far apart, and Keenes and Manvell were close together. Across subjects, therefore, the experimental manipulation of intercity distance was not confounded with materials.

Facts. After learning a map, the subjects learned facts about the cities on the maps. A list of 28 facts was compiled for each map. These facts were drawn from an 84-item pool that consisted of 28 facts from each of three categories of information that one might use to describe a city: its population (e.g., "51,000 people"), its principal industry (e.g., "mining companies"), and its quality of life (e.g., "dramatic theater"). Selection of a map's facts from these categories was random without replacement, with the restrictions that the three categories be equitably represented in a list and that no two items be very similar ("good schools" and "state university" would not both be allowed).

The facts were randomly assigned to city names on each map such that 12 cities were described by one fact (fan-1 condition) and 8 cities were described by two facts (fan- 2 condition). The fan manipulation was included to increase the number of possible stimuli in the location-judgment test. Fact assignments met the following constraints: (a) facts for fan- 2 cities always came from different descriptive categories; (b) no fact was assigned to more than one city (i.e., "fact fan" was always 1); and (c) a prime city and its target (e.g., "Corryton-Warren") were assigned the same number of facts.

Location judgments. A list of 22 city names and fact predicates was constructed for each of the two maps. Each base list contained eight prime-target pairs, two filler cities, and four filler facts. A second list was constructed from the first by (a) "reversing" the prime-target pairs in the base list such that the fact associated with an original target served as the new prime and the city belonging to an original prime served as the new target, and (b) replacing the filler items with new fillers. As an example of "reversing," consider Warren and Corryton in Figure 2. In the base list, "airport" (a fact about Corryton) might be used to prime "Warren," whereas in the "reversed" list, " 49,000 people" (a fact about Warren) might be used to prime "Corryton." A test list was constructed by repeating a base list four times and its "reversal" four times, yielding a total list of 176 items. The serial order of items within a base or a "reversed" list was randomized with each repetition, with the restriction that primes and targets were always in successive serial positions.

Items were randomly assigned to positions in each list, subject to the following restrictions: (a) targets appeared no earlier than the third position; (b) prime-target pairs assigned to the same condition never appeared sequentially in the list; (c) repetitions of items were separated by at least six trials; and (d) items from each county were distributed equitably across the list. The same test list was used for both versions of a map.

\section{Procedure}

Map learning. Each subject learned one map. Across subjects, two versions of each of two maps were used. Acquisition of a map took place in a series of study-test trials. On a study trial, the subjects were presented with a road map and were instructed to study the locations of its cities for $2 \mathrm{~min}$, in any way that they wished. On a test trial, the subjects were given a sheet of paper that contained the road grid but not the city names or their locations (the 
dots), and a separate list of the city names (in a random order). Their task was to place the cities on their correct locations, which were to be marked by dots. Test trials were self-paced. The alternation of study and test trials continued until the subjects could accurately place, two times, all cities within .25 in. of their correct locations.

Fact learning. After learning the map, the subjects committed to memory the facts associated with each of its cities. Acquisition of the facts proceeded in a series of study-test trials that were implemented on an IBM PC. On each study trial, the appropriate road map was displayed on the computer screen beneath the sentence (or sentences) corresponding to a city and its fact (or facts). The locations of all cities were designated by dots on the map, but only the location of the city currently being studied (e.g., "Liberty") was labeled. After studying a city and its fact(s) for a few seconds, the subjects pressed the space bar to erase the screen and to initiate presentation of the next city's fact(s). This procedure continued until all of the facts were presented, at which time the subjects were tested on their memory for the facts. The presentation order of cities and their facts was randomized for each study trial and for each subject.

During the self-paced test trials, the subjects were provided with a cue for each city on which they were about to be tested, consisting of a display of the road map on the computer screen. The locations of all cities were marked with dots but the dot corresponding to the to-be-tested city was also blinking on the screen. The subjects were instructed to recall which city belonged to the blinking location and to type in both the city name and its fact(s), followed by a press of the return key. This keypress initiated presentation of the correct fact(s), at which time the subjects scored their response(s) verbatim and recorded this result on the computer terminal. The instructions emphasized that subjects should be honest in their scoring, as success in this phase of the experiment was critical for success in the later phases. A subsequent press of the return key erased the screen and prompted the display of the next city's name and fan condition. This sequence continued until all facts had been tested. The test order of cities was randomized for each test trial.

A drop-out procedure was used in which a city was removed from the study trials after its fact(s) had been correctly recalled. The dropout criteria were two correct recalls for fan-1 cities and one correct recall (of both facts) for fan-2 cities. Preliminary research indicated that these criteria equated overall exposure to the fan- 1 and the fan- 2 city names. The alternation of study and test trials continued until these criteria were reached for all cities. The subjects were then given a written, cued-recall test for the facts, with the city names serving as cues. The entire cycle of study-test trials outlined above was repeated until the subjects could achieve perfect recall on this final test.

Location judgments. Following acquisition of the map and the facts, the subjects began the test phase of the experiment. A series of city names and fact predicates (e.g., " 49,000 people") was presented one item at a time on the computer screen. The subjects had to decide whether a city was in the upper or the lower county, or whether a fact predicate was associated with a city in the upper or the lower county. They responded by pressing the " $g$ " key for upper counties and the " $v$ " key for lower counties. An interval of 100 msec elapsed between a response to an item and the presentation of the next item. The instructions emphasized that subjects should respond as quickly and as accurately as possible. The location-judgment task was preceded by a practice test in which subjects discriminated names of U.S. states from names of foreign countries.

The subjects completed acquisition and test phases on a single day. Half of the subjects who learned a given map received one version and half received the other version. Furthermore, half of the subjects who learned a given map version were tested on one ordering (base-reversed-base-reversed, etc.) of the test list and half were tested on another ordering (reversed-base-reversed-base, etc.) of the test list.

\section{Results and Discussion}

Median correct response latencies and mean error rates were computed for each subject and each condition. Only correct responses preceded by correct responses were included in the median latencies. The means of these data are shown in Table 1.

The latency data in Table 1 evince a substantial distance effect $(112 \mathrm{msec})$ and hint at a fan effect $(26 \mathrm{msec})$. A within-subject analysis of variance on the median latencies showed that the distance effect was statistically reliable $\left[F(1,23)=11.12, M S_{e}=27,317, p<.005\right]$. The fan and the interaction effects, however, were not reliable $\left(M S_{\mathrm{e}}=32,955\right.$ for the interaction). Subsequent analyses showed that the pattern in Table 1 held for both maps, for a base list and its "reversal," and for all four repetitions of those lists.

Error rates followed the same general pattern as latencies. The distance effect $(2.86 \%)$ and the fan effect $(2.08 \%)$ were marginally significant $[F(1,23)=3.87$, $M S_{\mathrm{e}}=50.88, p=.06$, and $F(1,23)=3.54, M S_{\mathrm{e}}=$ $29.44, p=.07$, respectively]. The interaction effect did not approach significance $\left[F(1,23)=1.77, M S_{e}=33.12\right]$.

The results of Experiment 1 indicate that linguisticnonspatial information can be integrated in memory with knowledge about spatial structure. In Experiment 2, we explored whether experimentally learned factual information could be integrated with preexperimentally learned spatial information, namely, locations of buildings on a college campus.

This attempt to generalize to a naturally learned, largescale space is important for at least two reasons. First, if the results of Experiment 1 depend in some way on directed, intentional encoding of the maps, then they should not generalize to an environment that has been learned in a nondirected, incidental fashion. Second, there is evidence that very small spaces, such as maps, and large-scale spaces differ in the kinds of spatial behaviors they readily support (e.g., Presson, Delange, \& Hazelrigg, 1989; Presson \& Hazelrigg, 1984), suggesting that they may be encoded differently. It is not obvious, there-

Table 1

Response Latencies (RL; in Milliseconds) and Error Rates (ER; in Percentages) in Experiment 1

\begin{tabular}{cccccc}
\hline & \multicolumn{5}{c}{ Fan } \\
\cline { 2 - 4 } \cline { 5 - 6 } Distance & RL & ER & & RL & ER \\
\hline Close & 858 & 3.39 & & 894 & 3.91 \\
Far & 980 & 4.69 & & 996 & 8.33 \\
\hline
\end{tabular}

Note-Response latencies are means of medians; error rates are means of means. 
fore, that the findings of Experiment 1 will generalize to memories of a campus.

\section{EXPERIMENT 2}

In Experiment 2, we recruited as subjects sophomores, juniors, and seniors at Vanderbilt. These subjects were likely to have reasonably accurate knowledge of the locations of buildings on their campus. The subjects were required to learn facts about buildings on the campus. After learning the facts, they participated in a locationjudgment task very similar to the one used in Experiment 1 .

\section{Method}

\section{Subjects}

The subjects were 27 undergraduate students at Vanderbilt University. They were selected on a voluntary basis from an introductory psychology course and received both laboratory credit and monetary compensation for their participation. Because the experiment required that subjects be familiar with the Vanderbilt campus, only sophomores, juniors, and seniors were allowed to participate.

\section{Materials and Design}

Campuses. Vanderbilt University consists of two campuses, the main Vanderbilt campus and the Peabody campus. These campuses are separated by a major thoroughfare, which serves as a common boundary. (Wesley Hall is an exception; it is considered to be on the main Vanderbilt campus, even though it is on the same side of the street as Peabody.) A map of the campus is shown in Figure 1.

Twelve buildings were selected from the Peabody campus and 30 buildings were selected from the Vanderbilt campus. The 12 Peabody buildings were selected with the restriction that they be homogeneously distributed across the Peabody campus. The pool of Vanderbilt buildings consisted of 12 triads of buildings, each of which contained a target, a close prime, and a far prime. The average distance between targets and close primes was $339 \pm 47 \mathrm{ft}$ and the average distance between targets and far primes was $1,518 \pm 72 \mathrm{ft}$. Each of the 12 targets had a unique close prime but each target shared its far prime with one other target building. That is, there were six far primes, one for each of two target buildings. For example, the targets "Neely" and "Rand" shared the far prime "Wesley." Far primes were shared in this manner to reduce the number of buildings needed in the design. Prime buildings were chosen so that they shared a minimum of functional and semantic properties with target buildings. Selecting unrelated prime and target buildings was not difficult because neighboring buildings on the Vanderbilt campus typically do not have similar functions or house related departments.

Facts. A pool of facts was initially constructed for each building to provide an extensive description of its historical, functional, and architectural properties. One fact was selected for each building according to the following criteria: (a) that the fact be substantive (e.g., facts such as "has a water fountain on the third floor" were excluded); (b) that the fact associated with a target building not be functionally or semantically related to the facts associated with the target's close and far primes; and (c) that a comparable number of historical, functional, and architectural facts be represented in the list. Although all facts were true, the majority of them were obscure, and would not be known by undergraduates. For example, the presence of a swimming pool in the basement of Wesley Hall was not widely known because the pool was empty and the basement of Wesley was not accessible. No fact was associated with more than one building. The fan manipulation used in Experiment 1 was dropped in this experiment (as well as in Experiments 4 and
5) because sufficiently large numbers of building names and facts were available for the location-judgment test.

Location judgments. The subjects learned facts about slightly different subsets of Vanderbilt buildings (see below); consequently, two test lists were constructed. Each list contained 60 names: 18 building names and 18 fact predicates from the Vanderbilt campus, and 12 building names and 12 fact predicates from the Peabody campus. On each test list, six targets were immediately preceded by facts about close buildings and six targets were immediately preceded by facts about far buildings. Across the two lists, each target building appeared in the close and in the far condition. Assignment of items to positions in both lists was random, with the constraints that (a) targets appeared no earlier than the sixth position; (b) prime-target pairs assigned to the same distance conditions never appeared sequentially; (c) Vanderbilt and Peabody items were distributed equitably across the list; and (d) the distribution of filler items across the list was homogeneous.

\section{Procedure}

Fact learning. Subjects committed to memory the facts associated with the Vanderbilt and the Peabody buildings. Fact learning proceeded in a series of study-test trials that were implemented on an IBM PC. Unlike in Experiment 1, however, only the building name and its fact were displayed. The subjects were asked to imagine buildings when learning facts about them, but they did not see a map of the campus. The subjects learned one fact about each building; a fact had to be recalled twice before it was dropped from the study list. The order in which facts were studied and tested was randomized for each subject and for each trial.

Two groups of subjects were distinguished by which 24-item subset of Vanderbilt buildings they encountered in the experiment. Half of them studied facts associated with all 12 of the targets, all six of the far primes, and the six close primes that were paired with the 6 targets appearing in the close condition for those subjects. The other half of the subjects studied facts associated with all of the targets, all of the far primes, and the six close primes that were paired with the 6 targets appearing in the close condition for those subjects. Targets in the close condition for the first group of subjects appeared in the far condition for the second group of subjects, and vice versa. Assignment of subjects to these groups took place in a fixed rotation determined by the order in which subjects participated in the experiment.

Location judgments. Following the acquisition phase, subjects performed a location-judgment task. Specifically, a series of building names (e.g., "McTyeire") and fact predicates (e.g., "international house") was presented one item at a time on the computer screen. The subjects were required to decide whether each item was from the Vanderbilt or the Peabody campus. They pressed the " $m$ " key for Vanderbilt buildings and facts, and the " $z$ " key for Peabody buildings and facts. Instructions emphasized that subjects should respond as quickly and as accurately as possible. This task was preceded by a practice test in which subjects discriminated names of U.S. states from names of foreign countries.

\section{Results and Discussion}

Analyses of response latencies were conducted on the median correct response latencies for the targets in each condition. Only correct responses preceded by correct responses were included in the medians. Means of the median latencies and of the mean error rates were $888 \mathrm{msec}$ and $2.47 \%$ in the close condition, and $988 \mathrm{msec}$ and $1.85 \%$ in the far condition. The 100 -msec effect in latencies was statistically reliable $\left[F(1,26)=6.17, M S_{e}=\right.$ $21,679, p=.02]$. Error rates did not differ significantly $(F<1)$. These results, like those of Experiment 1, indi- 
cate that nonspatial and spatial information can be integrated in memory.

\section{DISCUSSION OF EXPERIMENTS 1 AND 2}

The results of Experiments 1 and 2 may not constitute evidence of knowledge integration if the following analysis of these experiments is valid.

Suppose that subjects' spatial and nonspatial memories were segregated. When subjects encountered a fact predicate in the location-judgment task, they might have consulted their memories of the facts to determine the city or the building with which the predicate was associated, and then consulted their spatial memories to determine where the item was located. The latter retrieval process would presumably activate neighboring items in spatial memory, thereby facilitating their subsequent retrieval. In short, priming could have occurred in the locationjudgment task even if the spatial and the nonspatial information were not encoded in a common memory representation.

In Experiments 3 and 4, we addressed this potential problem with the location-judgment task by changing the task demands. On each trial, the prime, which was always a fact predicate, was displayed for a brief period of time, and then was replaced by the target, which was always a building name. The subjects were told to read the prime and the target, but to make a location judgment for the target only. No response of any kind was made to the prime. In particular, there was no need for subjects to retrieve the name or the location of the building associated with the prime. If a distance effect is still observed under these conditions, then the knowledge integration account of the earlier results will be strengthened.

\section{EXPERIMENT 3}

Experiment 3 was a modified version of Experiment 1. The subjects learned a fictitious road map and then learned facts about cities on the map. Two major changes in procedures were made in this experiment. One change, as noted above, was that primes in the location-judgment test were displayed very briefly and no response was made to them. The second change was in the procedures employed during map learning.

In Experiment 1, the subjects learned the maps by studying them freely, which means that spatially proximal cities were also experienced close together in time. It is possible that the subjects created nonspatial associations between city names at the time of learning, and that these nonspatial associations mediated the priming effects (see, e.g., Clayton \& Habibi, 1991; McNamara, Halpin, \& Hardy, 1992; Sherman \& Lim, 1991). This problem was addressed in Experiment 3 by implementing map learning on a computer. The road grid was visible on the computer screen throughout learning, but no more than one city location was visible at a time. In particular, during the study and the test trials, the cities and their locations were displayed in a random order, with the constraint that neighboring cities (e.g., Warren and Corryton in Figure 2) were always separated by at least three other trials.

For example, if a section of the "logical" map looked like this:

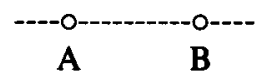

then on a given study trial, subjects would see the road grid with one location marked, as follows:

(The name of a location was always presented in the upper left corner of the computer display, not next to the location.) On a subsequent study trial, but at least three trials later, subjects might see the neighboring location, like so:

This procedure ensured that neighboring cities and locations were never experienced together, and hence, greatly reduced the likelihood that subjects would create nonspatial associations between them. Note that the spatial relation between two neighboring cities was never tested or pointed out in any way.

There are reasons to believe that this problem does not infect studies of naturally acquired spatial memories. It has been known for some time that spatial priming $\alpha$ curs in a recognition test when subjects' memories of an experimentally learned layout are tested, but that spatial priming does not occur in recognition when subjects' memories of their campus are tested; spatial priming does not seem to occur in naturally acquired spatial memories unless the task requires a spatial decision of some kind (e.g., Clayton \& Chattin, 1989; McNamara, Altarriba, Bendele, Johnson, \& Clayton, 1989). Sherman and Lim (1991) investigated the cause of this interaction, and showed that the pattern that we had obtained for naturally learned spatial layouts-spatial priming in location judgments but not in item recognition - could be obtained for an experimentally learned layout if spatially proximal locations were never experienced close together in time (see also McNamara et al., 1992). Sherman and Lim speculated that spatial and temporal contiguity are naturally uncoupled when people learn a campus because they often learn the spatial layout incidentally, using routes that do not force them to experience neighboring buildings close together in time. This characterization of how college campuses are learned may not hold in general, but it is particularly apt for the Vanderbilt campus because neighboring buildings typically are not functionally related, and all of the buildings used as targets can be accessed without passing through or near the prime buildings. (These issues will be explored in more detail in the General Discussion.) 


\section{Method}

Subjects

The subjects were 20 undergraduates at Vanderbilt University who participated for course credit.

\section{Materials and Design \\ Maps and facts. The maps and facts were identical to those used in Experiment 1. Unlike in Experiment 1, however, al] materials were presented on computer displays.}

Location judgments. Eight test lists were constructed to permute stimuli through the four experimental conditions. As in Experiment 1 , two versions of each of two structurally distinct maps were used; these versions differed in the assignment of city names to the close and to the far conditions. Two test lists (A and B) were constructed for each of these four maps. These lists differed only by the "reversal" of prime-target pairs (see Experiment 1); that is, in List A, "airport" (a fact about Corryton) might be used to prime "Warren," whereas in List B, "49,000 people" (a fact about Warren) might be used to prime "Corryton."

Each test list contained 44 prime-target pairs, eight in each of the four experimental conditions (distance $x$ fan) and 12 fillers. The eight experimental items in each condition comprised two unique prime-target pairs (e.g., "820,000 people-Manvell" and "electronics-Lytton') appearing four times each. Otherwise, the lists were constructed along the same lines as in Experiment 1. Each subject saw one test list. The eight test lists were assigned to subjects using a fixed rotation determined by the order in which subjects participated in the experiment.

\section{Procedure}

Map learning. Each subject learned one of the four maps constructed for Experiment 1 . The map road grids were displayed on a computer terminal using Hercules-compatible monochrome graphics. The road grid occupied a square of about $6 \times 6$ in. on a standard 12-in. diagonal monitor, and hence, was compressed in the vertical dimension relative to the map in Figure 2 . This compression changed the interpoint distances in the critical conditions, but pairs in the far condition were still farther apart than pairs in the close condition. On each study trial, the display contained the entire road grid (with the counties demarcated and named), the name of a single city in the upper left corner of the display, and the location of that city marked on the road grid. The city name and its location were presented for $3 \mathrm{sec}$, at which point a new city name and its location were displayed, and so on, until all 20 cities had been displayed. Cities were displayed in a random order, with the constraint that members of pairs of cities in the experimental conditions were presented at least three trials apart. In particular, cities in the close condition never appeared together or even sequentially in the learning protocol.

After all of the cities had been displayed, the subjects' memories were tested. They were cued with the location on the road grid, which was displayed for $3 \mathrm{sec}$. The screen was then erased, and the prompt "City?" appeared at the top of the screen; the subjects were to type in the name of the city. They were immediately informed whether the response was correct or incorrect, and if incorrect, what the correct city was. The subjects were then cued with the next location, and so on, until all 20 locations had been tested. Locations were tested in a random order, again with the constraint that members of experimental pairs were separated by at least three test trials. The study-test sequence was repeated until the subjects could correctly recall all of the city names twice.

Fact learning. After the subjects learned the map, they had to learn facts about cities on the map. As in Experiment 1, 12 cities were described by one fact ( $\operatorname{fan} 1)$ and 8 cities were described by two facts ( $\operatorname{fan} 2$ ). On each study trial, the computer display contained the entire road grid, the name of a ciry in the upper left comer, the location of that city marked on the road grid, and one or two facts displayed above the map at the very top of the screen. The subjects were allowed to study the display for as long as they wished, and could advance through the cities and their facts by pressing the space bar.

After the subjects had studied all 20 cities and their facts, their memories for the facts were tested. On each test trial, they were cued with a display that contained the road grid and a single blinking location. A press of the space bar caused the entire screen to be erased and the word "City:" to be displayed. The subjects were instructed to recall which city belonged in the blinking location and to type in its name. They were then prompted for the fact or the facts, which they also entered at the keyboard. After the subjects had entered the city name and its fact(s), the correct answers were displayed. As in previous experiments, they scored their own answers and entered the result at the keyboard. This sequence continued until all facts had been tested. The test order of cities was randomized for each test trial. The drop-out criteria were two correct recalls for fan-1 cities and one correct recall for fan- 2 cities.

Location judgments. In the location-judgment task, a fact predicate (e.g., "subway system") and a city name (e.g., "Afton") were presented on each trial. The subjects initiated each trial by pressing the space bar. One second later, a row of 10 asterisks was presented near the center of the screen. This fixation marker remained in view for $250 \mathrm{msec}$ and was followed by a 250 -msec blank inter$\mathrm{val}$. The prime was then displayed for $200 \mathrm{msec}$ and was followed by a 50 -msec blank interval. The target then appeared, and remained in view until the subject responded. The fixation marker, the prime, and the target all appeared at the same location on the screen. The subjects were instructed to read the prime and the target, but to decide only whether the target was in the upper or in the lower county. They pressed the " $\mathrm{m}$ " key for the upper county and the " $z$ " key for the lower county. Instructions emphasized that subjects should respond as quickly and as accurately as possible. Because we were concerned that the subjects might not attend to the prime, we had them recall it after responding to the target. A prompt appeared on the screen, and the subjects typed in their response using the keyboard. The computer displayed the correct answer below the response. The location-judgment task was preceded by a practice test in which the subjects discriminated names of U.S. states from names of foreign countries.

\section{Results and Discussion}

The means of median latencies and mean error rates are shown in Table 2 . The data from one subject were discarded because of excessively long latencies and high error rates in the location-judgment task. The data were submitted to within-subjects analyses of variance with fixed effects corresponding to distance (close vs. far) and to fan (1 vs. 2). The 145-msec effect of distance in latencies was reliable $\left[F(1,18)=4.33, M S_{t}=91,591, p<\right.$ $.05]$, but the effect of fan and the interaction were not $\left(M S_{e}=139,778\right.$ for the interaction). Error rates showed

Table 2

Response Latencies (RL; in Milliseconds) and Error Rates (ER; in Percentages) in Experiment 3

\begin{tabular}{cccccc}
\hline & \multicolumn{5}{c}{ Fan } \\
\cline { 2 - 4 } \cline { 5 - 6 } Distance & RL & ER & & RL & ER \\
\cline { 2 - 5 } & 1242 & 10.5 & & 1223 & 11.2 \\
Close & 1241 & 19.1 & & 1341 & 16.4 \\
\hline
\end{tabular}

Note-Response latencies are means of medians; error rates are means of means. 
the same pattern as latencies, although the effect of distance was only marginally significant $[F(1,18)=3.88$, $\left.M S_{\mathrm{e}}=233.9, p=.065\right]\left(M S_{\mathrm{c}}=324.8\right.$ for the interaction).

It is notable that response latencies were longer, error rates were higher, and variability was greater in Experiment 3 than in Experiment 1. These differences can probably be attributed to the fact that when the subjects learned the maps in Experiment 1, city names appeared in their correct spatial locations, whereas in Experiment 3, the names of the cities appeared outside of the bounds of the map itself. Thus, the names were probably less well integrated with the spatial structure, and hence, it was harder for the subjects to decide whether a city was in the upper or in the lower county.

The results of Experiment 3 militate against two potential criticisms of Experiment 1. First, the fact that the distance effect occurred even though neighboring cities were never experienced close together in time, argues that this effect was mediated by the spatial relation between the cities, not by some nonspatial association. Second, the presence of the distance effect even when the prime was presented briefly and no response to it was required, indicates that the spatial and the factual information were indeed integrated in memory.

\section{EXPERIMENT 4}

The purpose of Experiment 4 was to replicate Experiment 2 using the modified location-judgment task.

\section{Method}

\section{Subjects}

The subjects were 60 Vanderbilt undergraduates who participated in the experiment for course credit.

\section{Materials and Design}

Campuses and facts. The 42 buildings and 42 facts used in Experiment 2 were also used in Experiment 4. Unlike in Experiment 2, however, the subjects in Experiment 4 learned all 42 of these building-fact associations.

Location judgments. Three 30-trial base lists were constructed initially. Six experimental conditions were represented on each list.

In the three conditions of primary interest, a fact about a Vanderbilt building primed a Vanderbilt building name. These conditions differed as a function of the relation between the fact and the name: In the direct condition, a fact primed the name of the building with which the fact was associated (e.g., "dramatic theaterNeely"); in the close condition, a fact primed the name of a neighboring building (e.g., "World War I-Neely"); and in the far condition, a fact primed the name of a distant building (e.g., "swimming pool-Neely"). The direct priming condition was new to this experiment; it was included because of its possible importance in testing theories of retrieval (see the General Discussion for details). The 12 Vanderbilt target buildings were permuted through these three conditions across the three lists. Building names and facts were never repeated on a list.

In the three remaining conditions, the prime (a fact) was associated with a Vanderbilt building and the target was a Peabody building name, or the prime was associated with a Peabody building and the target was a Vanderbilt building name, or both the prime and the target were from the Peabody campus. There were eight, six, and four trials, respectively, in each of these conditions. The "distance" between the prime fact and the target building was not manipulated in these conditions, nor were items permuted through conditions.

These three base lists were then combined to form three 90 -trial test lists. The order of the base lists varied in a Latin square across the three test lists. Hence, the three test lists contained exactly the same items, but in a different order. Within a test list, each of the 12 target buildings appeared in the direct, the close, and the far priming conditions. The test lists were assigned to the subjects in a fixed rotation determined by the order in which subjects participated in the experiment.

\section{Procedure}

Fact learning. The subjects committed to memory the facts associated with the Vanderbilt and the Peabody buildings. The procedures were identical to those used in Experiment 2, except that they learned all 42 fact-building pairs.

Location judgments. In the location-judgment task, a fact predicate (e.g., "dramatic theater") and a building name (e.g., "Neely") were presented on each trial. The prime was displayed for $200 \mathrm{msec}$ and was followed by a 50-msec blank interval. The target then appeared, and remained in view until the subject responded. The subjects were instructed to read the prime and the target, but to decide only whether the target was on the main Vanderbilt campus or on the Peabody campus. They pressed the " $m$ "' key for Vanderbilt buildings and the " $z$ " key for Peabody buildings. Instructions emphasized that subjects should respond as quickly and as accurately as possible. As in Experiment 3, they were required to recall the prime after having responded to the target. The location-judgment task was preceded by a practice test in which the subjects discriminated names of U.S. states from names of foreign countries.

\section{Results and Discussion}

Median correct response latencies and mean error rates were computed for each subject and each of the three experimental conditions (direct, close, and far). The means of these data are shown in Table 3.

Median latencies were submitted to a one-way withinsubject analysis of variance. This analysis revealed that the effect of condition was statistically reliable $\left[F(2,118)=6.61, M S_{\mathrm{e}}=12,407, p<.002\right]$. Planned directional comparisons revealed that all three of the means were significantly different from each other. The same analysis on error rates also revealed a reliable effect of condition $\left[F(2,118)=6.68, M S_{\mathrm{e}}=24.67, p<\right.$ $.002]$. In particular, error rates in the close condition were higher than error rates in the other two conditions, which did not differ significantly. This result is troubling because it suggests that subjects were trading speed for accuracy. The exact nature of the speed-accuracy tradeoff is unclear. Subjects might have responded overly fast in

Table 3

Response Latencies (RL; in Milliseconds) and Error Rates (ER; in Percentages) in Experiment 4

\begin{tabular}{ccc}
\hline Condition & RL & ER \\
\hline Direct & 916 & 4.44 \\
Close & 951 & 7.64 \\
Far & 990 & 5.28 \\
\hline
\end{tabular}

Note-Response latencies are means of medians; error rates are means of means. 
the close condition, creating high error rates, or, alternatively, they might have responded too slowly in the far condition, creating an artificially low error rate. Either way, however, the pattern in error rates complicates interpretation of the latency data.

\section{EXPERIMENT 5}

The approach we took to dealing with the apparent speed-accuracy tradeoff was to force the subjects to monitor and control their speed of responding. As in Experiment 4, they learned facts about buildings on their campus and then received a primed location-judgment task. Unlike in Experiment 4, however, the subjects were trained to respond at a precise point in time after the presentation of the target building. Using this procedure, response latencies were no longer useful as a dependent measure; error rates were the measure of interest.

\section{Method}

Subjects

The subjects were 24 Vanderbilt undergraduates who participated in the experiment for course credit.

\section{Materials and Design}

The materials and design were identical to those used in Experiment 4.

\section{Procedure}

Fact learning. The fact-learning procedures were identical to those used in Experiment 4.

Response-deadline training. After the subjects had learned the facts, they received 60 trials of training in the response-deadline procedures. A lexical decision task was used for this training.

The subjects initiated each trial by pressing the space bar. One second after the space bar was depressed, a row of six plus signs separated by spaces appeared near the center of the screen. This fixation marker remained in view for $250 \mathrm{msec}$ and was followed by a 250 -msec blank interval. The prime was then displayed for $200 \mathrm{msec}$ and followed by a 50 -msec blank interval, at which point the target appeared. The fixation marker, the prime, and the target all appeared at the same location on the screen. After the target had been in view for $250 \mathrm{msec}$, a row of asterisks appeared on the line below the target. The subjects were instructed to respond exactly $300 \mathrm{msec}$ after the asterisks appeared on the screen. They were told that responding too quickly was just as bad as responding too slowly. The subjects pressed the " $m$ " key for words and the " $z$ " key for nonwords.

Shortly after responding $(500 \mathrm{msec})$, the subjects were asked to recall the prime. They typed in their answer using the computer keyboard and then checked their answer against the correct one, which was displayed on the screen.

After the subjects had recalled the prime, the response latency for that trial was displayed, and they were told whether their response was correct. Latencies were measured from the appearance of the response signal (the row of asterisks) to the occurrence of the response. The subjects were told to keep their response time on each trial as close to $300 \mathrm{msec}$ as possible.

Location judgments. The location-judgment task followed the lexical decision task. The procedures were identical to those used in training. In particular, total processing time on the target was limited to 550 msec (250-msec presentation + 300-msec response latency). This value is $60 \%$ of the mean in the direct priming condition of Experiment 4; it was chosen because it seemed sufficiently
Table 4

Response Latencies (RL; in Milliseconds) and Error Rates (ER; in Percentages) in Experiment 5

\begin{tabular}{ccc}
\hline Condition & RL & ER \\
\hline Direct & 275 & 4.86 \\
Close & 331 & 9.37 \\
Far & 322 & 13.9 \\
\hline
\end{tabular}

Note-Response latencies are means of medians; error rates are means of means.

stringent to produce errors but not so stringent that subjects would respond randomly.

\section{Results and Discussion}

Median response latencies (including both correct and incorrect responses) and mean error rates were computed for each subject and each of the three conditions. Means of these data are shown in Table 4.

The mean response latencies revealed a reliable effect of condition $\left[F(2,46)=9.83, M S_{\mathrm{e}}=2,204, p<.001\right]$. Responses in the direct priming condition were faster than responses in the other two conditions, which did not differ significantly. This result indicates that the obtained differences in error rates between the direct priming condition and the other two conditions probably underestimate the real differences. If the subjects had responded as quickly in the close and the far priming conditions as in the direct priming condition, then their error rates would have been even higher. Note, however, that the similarity of the means in the close and the far conditions indicates that the error rates in these conditions can be compared without qualifications.

The error rates in the three experimental conditions were also submitted to an analysis of variance, which indicated that the effects were statistically reliable $\left[F(2,46)=6.86, M S_{e}=71.33, p<.005\right]$. Pairwise comparisons indicated that all of the means differed from each other. Most important, the subjects had, on the average, about $4.5 \%$ more information in the close condition than in the far condition at the same point in time.'

\section{GENERAL DISCUSSION}

The results of these experiments were clear. Subjects' location judgments were faster, more accurate, or both, when primed by a fact about a neighboring city or building than when primed by a fact about a distant city or building. The only exception to this pattern occurred in Experiment 4, in which there seemed to be a speed-accuracy tradeoff. A subsequent experiment showed, however, that the results of Experiment 4 did not compromise the findings as a whole. Taken together, the results of all five experiments converge on the conclusion that spatial and nonspatial information can be integrated in the same memory representation.

We have two goals in the remainder of this paper. We first discuss why our results indicate that nonspatial information has been integrated with spatial information in 
a nontrivial way. We then conclude by examining the implications of our results for theories of priming.

One possible criticism of these experiments is that they simply demonstrate priming in a nonspatial associative structure. Although we have discussed this above, we want to reiterate the argument because the problem is important. Recall that in Experiment 3, map learning and fact learning were controlled in such a way that spatially contiguous cities never appeared close together in time. The only relationship between two neighboring cities, A and $B$, was the spatial one of being located on the same visual line (i.e., route) on the computer screen. This spatial relation was never pointed out, studied, or tested in any way, and it was presented implicitly because of the temporal lag. Nevertheless, when a fact about A primed a location judgment about $B$, the judgment was facilitated. Given that the connection between A and B almost had to be spatial, the task was explicitly spatial, but the fact was semantic and nonspatial, we would seem to have evidence of integration. ${ }^{2}$

Additional evidence against the nonspatial associative explanation can be garnered from recent experiments that have investigated priming in memories of naturally learned spatial environments (e.g., Clayton \& Chattin, 1989; McNamara, Altarriba, et al., 1989; Merrill \& Baird, 1987). In these experiments, prime and target buildings were selected so that they did not share functional or semantic properties. The subjects were given a recognition test in which they had to discriminate the names of real buildings on their campus from fake names; the consistent result has been that no spatial priming occurs. This result also can be obtained when subjects learn an artificial spatial layout in an experimental setting if spatially contiguous objects are never experienced close together in time (Clayton \& Habibi, 1991; McNamara et al., 1992; Sherman \& Lim, 1991). If we assume that association in memory leads to priming in recognition, then these results indicate that associations did not exist between memories of neighboring buildings. Thus, to account for priming between a fact about Building $A$ and a location judgment on Building $B$, the fact must be integrated with whatever representation supports priming in the location-judgment task. We contend that this representation is spatial. Importantly, spatial priming occurs in location judgments even when spatially contiguous objects are not experienced close together in time (McNamara et al., 1992; Sherman \& Lim, 1991).

In another paper (McNamara et al., 1992), we present evidence that spatial memories contain at least two isolable components: A hierarchical nonmetric representation that encodes categorical spatial relations, such as relative location (e.g., next to), and a metric spatial representation that encodes metric spatial information, such as interpoint distances (for related models, see Kosslyn, 1987, and Huttenlocher, Hedges, \& Duncan, 1991). Moreover, our results suggested that location judgments tapped the metric spatial representation of the space, whereas recognition tapped the nonmetric representation of the space.
This theoretical framework accounts for a number of important results, including the much discussed results on naturally acquired spatial memories: Spatial priming occurs in location judgments because the task requires subjects to access their metric spatial representations; spatial priming does not occur in recognition because people do not usually encode the location of one building with respect to its neighbors in a categorical fashion, as in "Alumni Hall is next to Neely" (or at least our subjects did not encode these spatial relations between the buildings that we used as primes and targets).

In the context of this theoretical framework, the current findings indicate that facts about cities and buildings were integrated in some way with the metric spatial representation, otherwise priming would not be expected in the location-judgment task. The exact nature of this integration is an undecided issue. If the metric representation is analog in format, then the facts may be associated in some way with analog representations of location. It is not obvious, however, how these kinds of associations could be implemented. On the other hand, if the metric representation is coded in an amodal conceptual format (e.g., propositions), then the mechanism of integration is clear. Our data cannot decide between these two alternatives. The important point, though, is that the priming results show that nonspatial facts and information about spatial structure were "connected" in memory.

The scope of the present work is not limited to theories of spatial memory. Our results show that a basal assumption of the memory impairment hypothesis (Loftus, 1975; Loftus et al., 1978) is reasonable. The present data do not, of course, offer any support whatsoever for memory impairment as an explanation of the misinformation effect; they simply vindicate one of its presuppositions. These results also confirm an implicit assumption of mental model theories of reading comprehension; namely, that spatial and nonspatial information can be integrated in the same memory representation. Glenberg and Langston (1992) have obtained results similar to ours using different materials and methods. This convergence of outcomes indicates that the findings are quite robust.

Our data also may be relevant to current theories of associative priming. Priming effects of the kind reported in this paper have typically been attributed to spreading activation (e.g., Anderson, 1983; Collins \& Loftus, 1975; Quillian, 1967). It has been argued, however, that priming may be caused by the content of retrieval cues rather than by spreading activation (e.g., Dosher \& Rosedale, 1989; Ratcliff \& McKoon, 1988). According to these "compound-cue" models, memory is searched with a cue that contains information about the prime and the target. Several theories of memory (e.g., Gillund \& Shiffrin, 1984; Hintzman, 1986; Murdock, 1982) predict that the familiarity of a compound retrieval cue will be higher if the prime and the target are related in some way, than if they are unrelated. Familiarity can be mapped into response time and accuracy so as to produce priming effects (e.g., Ratcliff, 1978). 
One line of evidence that may distinguish these theories is that concerning the relation between priming and distance in the memory representation. Distance refers to the number of nodes, links, or associative "steps" intervening between the prime and the target in memory. Spreading-activation theories predict that priming should decrease smoothly with distance (e.g., Anderson \& Pirolli, 1984). Nonspreading-activation theories, however, predict no such relation. When combined with the compound-cue model, SAM (Gillund \& Shiffrin, 1984) predicts that priming will occur if items are directly associated (e.g., "lion-tiger") or are separated by two associative steps (e.g., "lion-stripes") but not if they are separated by three or more steps (e.g., "mane-stripes"); MINERVA-2 (Hintzman, 1986) and TODAM (Murdock, 1982), on the other hand, predict that priming will occur only if items are directly associated in memory (see Ratcliff \& McKoon, 1988, for details)

Early studies indicated that two-step, or "mediated" priming ("lion-stripes") did not occut in lexical decisions (Balota \& Lorch, 1986; de Groot, 1983), although there was evidence that mediated priming occurred in naming (Balota \& Lorch, 1986). More recently, McNamara and Altarriba (1988) showed that mediated priming can be obtained in lexical decisions. The present studies buttress these findings. The critical result in all of the experiments was priming between a fact about one city or building and the name of a neighboring city or building. These facts and names were separated by at least two associative steps. ${ }^{3}$ Note also that in Experiments 4 and 5, direct priming (e.g., "dramatic theater-Neely") was significantly larger than indirect priming (e.g. " "World War I-Neely"). These results are predicted by spreading-activation theories and by one of the nonspreading-activation theories, SAM.

Although the present results are consistent with SAM (when it is combined with the compound cue model), other data are not. There is evidence that the range of priming may be as large as three steps (McNamara, in press-b). These and other results (McNamara, in press-a) pose difficulties to nonspreading-activation theories of priming, and suggest that a rejection of spreading-activation mechanisms may be premature.

\section{REFERENCES}

Anderson, J. R. (1983). The architecture of cognition. Cambridge, MA: Harvard University Press.

Anderson, J. R., \& Pirolti, P. L. (1984). Spread of activation. Journal of Experimental Psychology: Learning. Memory, \& Cognition, 10, 791-798.

Bamp, J. C., Merrill, A. A., Tannenbaum, J. (1979). Studies of the cognitive representation of spatial relations: II. A familiar environment. Joumal of Experimental Psychology: General, 108, 92-98.

BALOTA, D. A., \& LORCH, R. F. (1986). Depth of automatic spreading activation: Mediated priming effects in pronunciation but not in lexical decisions. Joumal of Experimental Psychology: Learning, Memory, \& Cognition, 12, 336-345.

BEL1, R. F. (1989). Influences of misleading postevenl information: Misinformation interference and acceptance. Joumal of Experimental Psychology: General, 118, 72-85
Bower, G. H. Karlin, M. B., Dueck, A. (1975). Comprehension and memory for pictures. Memory \& Cognition, 3, 216-220.

Bransford, J. D., Barclay, J. R., Franks, J. J. (1972). Sentence memory: A constructive versus interpretive approach. Cognitive Psychology. 3, 193-209.

Carmichael, L., Hugan, H. P. \& Walter, A. (1932). An experimental study of the effect of language on the reproduction of visually perceived form. Joumal of Experimental Psychology, 15, 73-86

Clayton, K. N., Chatrin, D. (1989). Spatial and semantic priming effects in tests of spatial knowledge. Joumal of Experimental Psychology: Leaming, Memory, \& Cognition, 15, 495-506

Clayton, K. N. . HabiBi, A. (1991). Contribution of temporal contiguity to the spatial priming effect. Journal of Experimental Psychology: Learning, Memory, \& Cognition, 17, 263-271.

Collins, A. M. L LofTUS, E. F. (1975). A spreading-activation theory of semantic processing. Psychological Review, 82, 407-428.

DANIEL, T. C. (1972). Nature of the effect of verbal labels on recognition memory for form. Journal of Experimental Psychology, 96, 152-157.

DE GROOT, A. M. B. (1983). The range of automatic spreading activation in word priming. Joumal of Verbal Learning Vertal Behavior, 22, 417-436.

Doshen, B. A. . Rosedale, G. (1989). Integrated retrieval cues as a mechanism for priming in retrieval from memory. Journal of Experimental Psychology: General, 118, 191-211.

FrankLIN, N., TVersky, B. (1990). Searching imagined environments. Joumal of Experimental Psychology: General. 119, 63-76.

GENTNER, D. . LoFTus, E. F. (1979). Integration of verbal and visual information as evidenced by distortions in picture memory. American Journal of Psychology, 92, 363-375.

Gillund, G., Shiffrin, R. M. (1984). A retrieval model for both recognition and recall. Psychological Review, 91, 1-67.

GlenberG, A. M., LANGston, W. E. (1992). Comprehension of illustrated text Pictures help to build mental models. Joumal of Memory \& Language, 31, 129-151.

GlenbenG, A. M., Meyer, M., \&indem, K. (1987). Mental models contribute to Joregrounding during text comprehension. Journal of Memory \& Language, 26, 69-83.

Hintzman, D. L. (1986). "Schema abstraction" in a multiple-trace memory model. Psychological Review, 93, 411-428.

Hirtle, S. C. . Mascolo, M. F. (1986). Effect of semantic clustering on the mexnory of spatial locations. Joumal of Experimental Psychology: Leaming, Memory, \& Cognition, 12, 182-189

Huttenlocher, J., Hedges, L. V., Duncan, S. (1991). Categories and particulars; Prototype effects in estimating spatial location. Psychological Review, 98, 352-376.

Johnson-Lairo, P. N. (1983). Mental models. Cambridge, MA: Harvard University Press.

Kosslyn, S. M. (1987). Seeing and imagining in the cerebral hemispheres: A computational approach. Psychological Review, 94, 148-175.

Kosslyn, S. M. Ball, T. M., \& Reiser, B. J. (1978). Visual images preserve metric spatial information: Evidence from studies of image scanning. Joumal of Experimental Psychology: Human Perception \& Pefiomance, 4, 47-60.

Lofrus, E. F. (1975). Leading questions and the eyewitness report. Cognitive Psychology, 7, 560-572.

LofTus, E. F., Miller, D. G., Burns, H. J. (1978). Semantic integration of verbal information into a visual memory. Jourmal of $E x$ perimental Psychology: Human Learning \& Memory, 4, 19-31.

MANI, K., Johnson-LAIRD, P. N. (1982). The mental representation of spatial descriptions. Memory \& Cognition, 10, 181-187.

McCloskey, M., \& Zaragoza, M. (1985). Misleading postevent information and memory for events: Arguments and evidence against memory impairment hypotheses. Joumal of Experimental Psychology: General, 114, 1-16.

McNamara, T. P. (1986). Mental representations of spatial relations. Cognitive Psychology, 18, 87-121.

McNAmArA, T. P. (in press-a). Priming and constraints it places on theories of remory and retrieval. Psychological Review.

McNamara, T. P. (in press-b). Theories of priming: I. Associative dis- 
tance and lag. Journal of Experimental Psychology: Learning, Memory, \& Cognition.

McNamara, T. P., \& Altarriba, J. (1988). Depth of spreading activation revisited: Semantic mediated priming occurs in lexical decisions. Journal of Memory \& Language, 27, 559.

McNamara, T. P., Altarriba, J., Bendele, M., Johnson, S. C., \& Clayton, K. N. (1989). Constraints on priming in spatial memory Naturally learned versus experimentally learned environments. Memory \& Cognition, 17, 444-453.

McNamara, T. P., Halpin, J. A., Hardy, J. K. (1992). Spatial and temporal contributions to the structure of spatial memory. Journal of Experimental Psychology: Learning, Memory, \& Cognition, $18,555-564$

McNamara, T. P., Hardy, J. K., Hirtle, S. C. (1989). Subjective hierarchies in spatial memory. Journal of Experimental Psychology: Learning, Memory, \& Cognition, 15, 211-227.

McNamara, T. P., LeSueur, L. L. (1989). Mental representations of spatial and nonspatial relations. Quarterly Journal of Experimental Psychology, 41A, 215-233.

McNamara, T. P., Miller, D. L., \& Bransford, J. D. (1991). Mental models and reading comprehension. In R. Barr, M. L. Kamil, P. Mosenthal, \& P. D. Pearson (Eds.), Handbook of reading research (Vol. 2, pp. 490-511). New York: Longman.

MCNAMARA, T. P., RATClifF, R., \& MCKoON, G. (1984). The mental representation of knowledge acquired from maps. Journal of $E x-$ perimental Psychology: Leaming, Memory, \& Cognition, 10, 723-732.

MerRILl, A. A., BAIRD, J. C. (1987). Semantic and spatial factors in environmental memory. Memory \& Cognition, 15, 101-108.

Morrow, D. G., Bower, G. H., \& GreensPan, S. L. (1989). Updating situation models during narrative comprehension. Journal of Memory \& Language, 28, 292-312.

Morrow, D. G., Greenspan, S. L., \& Bower, G. H. (1987). Accessibility and situation models in narrative comprehension. Journal of Memory \& Language, 26, 165-187.

Murdock, B. B. (1982). A theory for the storage and retrieval of item and associative information. Psychological Review, 89, 609-626.

Pezdek, K. (1977). Cross-modality semantic integration of sentence and picture memory. Journal of Experimental Psychology: Human Learning \& Memory, 3, 515-524.

PoSNER, M. I., \& SNyder, C. R. (1975a). Attention and cognitive control. In R. L. Solso (Ed.), Information processing and cognition (pp. 55-85). Hillsdale, NJ: Erlbaum.

Posner, M. I., SNYder, C. R. (1975b). Facilitation and inhibition in the processing of signals. In P. M. A. Rabbitt (Ed.), Attention and performance V (pp. 669-682). London: Academic Press.

Presson, C. C., Delange, N., Hazelrigg, M. D. (1989). Orientation specificity in spatial memory: What makes a path different from a map of the path? Journal of Experimental Psychology: Learning, Memory, \& Cognition, 15, 887-897.

Presson, C. C., \& Hazelrigg, M. D. (1984). Building spatial representations through primary and secondary learning. Journal of Experimental Psychology: Leaming, Memory, \& Cognition, 10, 716-722.

Quillian, M. R. (1967). Word concepts: A theory and simulation of some basic semantic capabilities. Behavioral Science, 12, 410-430.

Ratclif, R. (1978). A theory of memory retrieval. Psychological Review, 85, 59-108.
Ratcuff, R., McKoon, G. (1981). Automatic and strategic priming in recognition. Journal of Verbal Learming \& Verbal Behavior, 20, 204-215.

RATCLIF, R., \& MCKoon, G. (1988). A retrieval theory of priming in memory. Psychological Review, 95, 385-408.

Rosenberg, S., \& Simon, H. A. (1977). Modelling semantic memory: Effects of presenting semantic information in different modalities. Cognitive Psychology, 9, 293-325.

Sadalla, E. K., Staplin, L. J., \& Burroughs, W. J. (1979). Retrieval processes in distance cognition. Memory \& Cognition, 7, 291-296.

SANFORD, A. J., \&ARROD, S. C. (1981). Understanding written language. New York: Wiley.

ShARP, D. M., MCNAMARA, T. P. (1991). Spatial mental models in narrative comprehension: Now you see them, now you don't. Manuscript submitted for publication.

Sherman, R. C., \& LiM, K. M. (1991). Determinants of spatial priming in environmental memory. Memory \& Cognition, 19, 283-292.

STEVENS, A., \& CouPE, P. (1978). Distortions in judged spatial relations. Cognitive Psychology, 10, 422-437.

THORNDYKE, P. W. (1981). Distance estimation from cognitive maps. Cognitive Psychology, 13, 526-550.

TulviNG, E. (1976). Ecphoric processes in recall and recognition. In J. Brown (Ed.), Recall and recognition. London: Wiley.

TVERSKY, B., \& TUCHIN, M. (1989). A reconciliation of the evidence on eyewitness testimony: Comments on McCloskey and Zaragoza. Journal of Experimental Psychology: General, 118, 86-91.

VAN DiJK, T. A., \& KINTSCH, W. (1983). Strategies of discourse comprehension. New York: Academic Press.

\section{NOTES}

1. At the end of the session in Experiments 2, 4, and 5, the subjects were tested on their knowledge of the locations of buildings on the Vanderbilt campus. They were given a map of the campus on which buildings were circled but not labeled. The subjects had to recall the names of all of the circled buildings. There was no evidence in any experiment that the pattern of results in the location-judgment task depended on how well the subjects knew the campus, but the average level of performance was high ( $82 \%$ correct).

2. We have assumed so far that the facts are semantic and nonspatial. It is possible, however, that the subjects interpreted the facts as semantically empty visual labels, and simply integrated this visual label with the spatial representation. We cannot rule out this possibility, but given that the fact predicates used as primes were presented in sentences, it does not seem very likely.

3. It is possible that the subjects associated facts with the location of the target building and the locations of its neighbors, in which case the associative distance between a target fact and a neighboring building would be one step. This seems unlikely, however, given the learning procedures used, especially in Experiment 3.

(Manuscript received August 12, 1991; revision accepted for publication December 11, 1991.) 